\title{
Interventions for solving the problem of water resources
}

\author{
Yiming Sun \\ School of Power engineering, North China Electric Power University, Baoding 071003, China; \\ 364740356@qq.com
}

Keywords: Interventions, water resource, interventions.

\begin{abstract}
When analyzing the physical shortage, we use We plan to intervene from supply and demand for solving the problem of water resources, using synergetic theory and AHP to get the different intervention's effect on alleviating water crisis. And we constitute two interventions making a new direction and possibility for water resource.
\end{abstract}

\section{Introduction}

In the water shortage map offered by the UN, we select Shenyang, which is a city of China with complex water situation. The uneven distribution of water resources in Liaoning Province has seriously restricted the sustainable development of economy and the improvement of the living standard of the residents. Many cities and towns are restricted by water resources.

Peak seasons of supplied water and demanded water usually are not corresponding and even always contradictive. In this way, there will emerge a water shortage in the whole area, oppositely balance in partial area, or a balance in the whole area and shortage in partial area. Consequently, we need to assign the supply and demand distribution to each month to study the annual changes in the region.

The relationship between supply and demand determines the existence of the two opposite relationship. We can start from the two aspects of demand and supply to set up the intervention plan to relieve the water shortage. Increasing the supply of water can be developed from the development of non-conventional water resources and construction of water resources project.

The improvement of demanded water can be effected by water pollution prevention and control, improvement of residents' awareness and efficiency of agricultural irrigation.

\section{Interventions for solving the problem of water resources}

\subsection{Supply of water:}

Transferring Water from East to West Policy ${ }^{[1]}$ supplies water for surrounding of Shenyang from Hun River.

This policy makes full use of the underground reservoir, especially the underground water layer in the groundwater funnel area to store the surface water.

This policy adjusts water using time, building a reservoir to store water in flood season. In the water resource system using pondage action, according to balance of water, then we can get the differential equation ${ }^{[2]}$

$$
\frac{\mathrm{dw}}{d t}=f(t)-o(t)
$$

In this equation:

W refers to the water storage capacity of the water resource system, and is a function of time.

$f(t)$ is the water inflow of the water resource system at t time. $f(t)$ is a random variable, it is a random fluctuation term of the system.

$\mathrm{o}(\mathrm{t})$ refers to the output of the water resource system at $\mathrm{t}$ time.

The amount of water consists of system water consumption and water losses. We assume that some new water sources with stochastic characteristics are developed or introduced in this area,. Then the differential equation of water balance can be written as 


$$
\frac{\mathrm{dw}}{d t}=f(t)-o(t)+a
$$

In this equation, $\mathrm{o}(\mathrm{t})$ and $\mathrm{w}$ are related to a, so we can describe that $N(w, a)=a-o(t)$.

Then, the differential equation can be written as

$$
\frac{d w}{d t}=f(t)+N(w, a)
$$

In this, $\mathrm{N}(\mathrm{w}, \mathrm{a})$ is a first order nonlinear equation function. The equation can reflect the changes of water resources after the increase of water supply measures in the area. We can obtain the value of a by searching on the internet and analyzing the data that we searched. The value of a is

$$
3.65 \times 10^{8}+2.046 \times 10^{9}=2.411 \times 10^{9}\left(\mathrm{~m}^{3} / \mathrm{a}\right)
$$

\subsection{Demand of water}

We utilize the AHP ${ }^{[3-4]}$ to construct pair wise comparison matrices. We can get judgment matrix from factor set $\mathrm{U}$, get the characteristic root and corresponding characteristic vector by Root Method. $\mathrm{U}=\left\{u_{1}, u_{2}, u_{3}\right\}$, Three intervention schemes are used as judgment factors, and the intervention degree of the two factors were compared: We assume 1 9 stand for the intensity of intervention becoming from low to high. Their reciprocals stand for the intensity of non-intervention. Then we can get the judgment of matrix

$$
U=\left\{\begin{array}{ccc}
1 & 2 & 4 \\
\frac{1}{2} & 1 & 2 \\
\frac{1}{4} & \frac{1}{2} & 1
\end{array}\right\}
$$

500 sample judgment matrix calculations of the average random consistency index test values are shown as the matrix:

Table 1: Average Random Consistency Index

\begin{tabular}{|c|c|c|c|c|c|c|c|c|}
\hline Order & 1 & 2 & 3 & 4 & 5 & 6 & 7 & 8 \\
\hline RI & 0 & 0 & 0.58 & 0.9 & 1.12 & 1.24 & 1.32 & 1.41 \\
\hline
\end{tabular}

Solve the approximate value of each weight vector by

$a_{i}^{\prime}=\sqrt[3]{\prod_{i=1}^{3} a_{i j}}$

Then we get the calculation of $\mathrm{a}_{1}{ }^{\prime} \mathrm{a}_{2}{ }^{\prime} \mathrm{a}_{3}{ }^{\prime}$

$a_{1}^{\prime}=2 \quad a_{2}^{\prime}=1 \quad a_{3}^{\prime}=0.5$

Normalize the $a_{i}$, we can get the value of $a_{i}$

$\mathrm{a}_{i}=\frac{a_{i}^{\prime}}{\sum_{\mathrm{k}=1}^{3} a_{k}^{\prime}}$

$a_{1}^{\prime}=0.571 \quad a_{2}^{\prime}=0.286 \quad a_{3}^{\prime}=0.143$

We use consistency ratio to test the value of $a_{i}$, we can know

$$
\lambda_{\mathrm{i}}=\frac{\sum_{i=1}^{3} \mathrm{a}_{\mathrm{ij}} a_{j}}{a_{i}}=3
$$

The maximum eigenvalueis

$$
\lambda_{\text {max }}=\frac{\sum_{i=1}^{3} \lambda_{i}}{3}=3
$$


Check the Consistency testing value

$$
\begin{aligned}
& C I=\frac{\lambda-n}{n-1}=\frac{3-3}{3-1}=0 \\
& C R=\frac{C I-0}{R I}=0<0.1
\end{aligned}
$$

It illustrates there isn't logistical error with $\mathrm{a}_{\mathrm{i}}$.

\section{Advantages and disadvantages}

In the control of water saving, the controls of water consumption per capita, industrial pollution control, agricultural irrigation and other aspects reduce the demand for water. There is a strongly regulatory role in the sustainable development of water resources. However, because of inadequate consideration of comprehensive measures of water saving, there exist gaps on the prediction of water saving capacity.

\section{Summary}

The exceeding exploitation of water resources also pays a high environmental and ecological cost. We constitute two interventions from supply and demand, and made an evaluation of them. Transferring Water from East to West Policy alleviates the burden of surface water use and meanwhile increases the water supply of the diversion river basin. But Liaoning province is regarded as a province lacking of water. Water diversion project costs a lot, and is susceptible to the impact of the terrain factors, so it is difficult to utilize. And underground reservoirs in the current situation of over exploitation are difficult to large-scale construct.

\section{References}

[1] Youguang Huo, With the eastern route of the yalu river ShuiNa project water environment analysis and optimization decision [J]. Journal of xi 'an jiaotong university: The natural version 1999, 19(2): 36- 41.

[2] M D Swanson,M Kobayashi,A H Tewfik. Multimedia data embedding and watermarking technologies, Proceedings for the IEEE, 1998

[3] Senn S. Testing for baseline balance in clinical trials. Statistics in M edi-cine, 1994, 13: 17151726.

[4]DEImai KKing Get al.M atching as nonparametric preprocessing in parametric causal inference. Political Analysis, 2007, 15: 199-236. 